\title{
Diverse effects of $c$-src deficiency on molar tooth development and eruption in mice*
}

\author{
Atsushi Miyata ${ }^{1,2}$, Otto Baba², Tsuyoshi Oda ${ }^{3}$, Isao Ishikawa ${ }^{4}$, and Yoshiro Takano² \\ Section of ${ }^{1}$ Periodontology, and ${ }^{2}$ Biostructural Science, Department of Hard Tissue Engineering, Tokyo Medical and \\ Dental University Graduate School, Tokyo; ${ }^{3}$ Central Research Institute of Electric Power Industry, Chiba; and \\ ${ }^{4}$ Institute of Advanced Biomedical Engineering and Science, Tokyo Women's Medical University, Tokyo, Japan
}

Summary. $C$-src deficiency is characterized by osteopetrosis due to impaired bone resorption by hypofunctional osteoclasts and the resultant failure of tooth eruption. In preliminary observations, we frequently encountered erupted molars in $c$-src deficient mice unlike in other osteopetrotic animals. Here we examine the effects of $c$ src deficiency on the development of molar teeth with an emphasis on the spatial relation of growing teeth with the surrounding bones.

In $c$-src deficient mice, the magnitude of tooth impaction differed considerably among the types of molars; all maxillary 1st molars were totally impacted deep in the alveolar sockets, whereas most mandibular 1st molars fully erupted into oral cavity. Distribution of osteoclasts in the alveolar bone was identical among all types of molars, and electron microscopy revealed signs of bone resorbing activity in these osteoclasts despite the absence of a ruffled border. From early development, the alveolar space was much narrower in the upper molar tooth germs than in the lower ones in both wild type and homozygous animals,

Received January 17, 2007

* This study was supported in part by a Grant-in-Aid for Scientific Research from Japan Society for the Promotion of Science (18390485) and Ministry of Education, Science, Sports and Culture of Japan (18659536).

Address for correspondence: Prof. Yoshiro Takano, D.D.S., Ph.D., Section of Biostructural Science, Department of Hard Tissue Engineering, Tokyo Medical and Dental University Graduate School, 1-5-45 Yushima, Bunkyo-ku, Tokyo 1138549 Japan

Tel: +81-3-5803-5439, Fax: +81-3-5803-5439

E-mail: takanoy.bss@tmd.ac.jp and particularly so in the upper 1st molars.

Current observations thus indicate a significant contribution of "hypofunctional osteoclasts" in $c$-src deficient mice in molar tooth development except for the upper 1st molars, which appear to require highly functional osteoclasts to gain sufficient space for them to grow normally. Taken together, these findings on the seemingly tooth-type specific effects of $c$-src deficiency on the development and eruption of molar teeth in $c$-src deficient mice can be attributed to the given differential spatial relation of the respective tooth germs with the surrounding bones in the presence of hypofunctional osteoclasts.

\section{Introduction}

The $c$-src proto-oncogene is a normal cellular counterpart of the $\mathrm{v}$-src oncogene responsible for the transforming protein of the Rous sarcoma virus (Stehelin et al., 1976). The $c$-src gene belongs to a highly conserved family of tyrosine kinases (Eiseman et al., 1990), encodes a $60 \mathrm{kDa}$ tyrosine protein kinase (PP60c-src) localized on the cytoplasmic face of cellular membranes, and is believed to play a role in signal transduction mechanisms involved in cell growth and differentiation (Cantley et al., 1991).

Osteoclasts in src-deficient mice fail to form a ruffled border. Treatment with stimulators of bone resorption increases the number of osteoclasts in these animals (Yoshida et al., 1990), but the osteoclasts lack a ruffled border and hence form no resorption lacunae (Boyce $e t$ al., 1992, 1993). Consequently, the primary phenotype in mice lacking the $c$-src gene is osteopetrosis (Soriano et $a l ., 1991)$ resulting from impaired bone resorption by the hypofunctional osteoclasts (Tanaka et al., 1992).

Failure of tooth eruption is a common feature among 
the various types of osteopetrotic animals. In these animals, the eruption pathway of tooth is not properly formed due to the absence of functional osteoclasts (Helfrich, 2005). With regard to the influence of $c$-src deficiency on tooth development, much attention was first focused on the odontomatous lesions associated with the incisors, which failed to erupt in these animals (Tiffee et al., 1999). Consequently, observations on molar tooth development in $c$-src deficient mice in previous reports were limited and rather confusing. Tiffee et al. (1999) examined 4-week-old $c$-src deficient mice and reported a failure of eruption for both incisors and molars, without presenting any actual data of the latter tooth type. Amling et al. (2000) presented X-ray profiles of the skulls of aging $c$-src knockout mice and showed seemingly erupted molars but withheld comments on this.

Tooth eruption is a complex biological process in which the growing tooth germs first migrate from the original site of development within the jaw bones and then shift to a vertical eruptive movement until they reach their final functional positions in the occlusal plane (Marks, 1995; Marks et al., 1996; Jung et al., 2003). Tooth eruption is therefore divided into two simultaneous and synchronous phases: one of formation of the eruption pathway, and the second of vertical tooth movement toward the oral cavity (TenCate, 1998). In order for the eruption pathways to form within the jaw bones, the recruitment of osteoclast precursors and their differentiation and activation at the site of prospective bone resorption are required (Wise $e t$ al., 2002). In fact, over half of the alveolar bone surfaces overlying the crown region of the erupting teeth are occupied by osteoclasts during the process (Marks et al., 1983). Colony stimulating factor-1 (CSF-1), epidermal growth factor (EGF), c-Fos, interleukin-1 $\alpha$, monocyte chemotactic protein-1 (MCP-1), NF- $\kappa \mathrm{B}$, osteoprotegerin (OPG), parathyroid hormone-related protein (PTHrP), receptor activator of $\mathrm{NF}-\kappa \mathrm{B}$ ligand (RANKL), and transforming growth factor (TGF)- $\beta 1$ have all been suggested to contribute to this process (Wise et al., 2002). For the vertical tooth movement, the importance of the dental follicle and periodontal ligament has been proposed, and the fibroblasts derived from these tissues are likely to provide the force for the tooth movement (TenCate, 1998).

Through our preliminary $\mathrm{X}$-ray surveillance of $c$ src deficient mice, we noted a distinct difference in the magnitude of suppression of tooth eruption among the different types of molars, ranging from full impaction to full eruption, unlike in other types of osteopetrotic animals (Philbrick et al., 1998; Yoda et al., 2004). The apparent eruption of the molar teeth in $c$-src deficient mice was unpredictable since the osteoclasts in these animals have been known to be devoid of a ruffled border and hence lack or only have negligible resorption activity of hard tissues in vitro (Boyce et al., 1992).

In this study, we therefore sought to pursue a longterm observation of the developmental process of the molar teeth of $c$-src knockout mice, with an emphasis on the spatial-temporal relationship between the growing tooth germs and the surrounding bones as well as the distribution of osteoclasts in the eruption pathways, in order to gain insights into the physiological roles of $c$-src in the development of teeth and periodontal tissues.

\section{Materials and Methods}

All animal experiments were approved by the Animal Welfare Committee of the Central Research Institute of the Electric Power Industry and that of the Tokyo Medical and Dental University.

\section{Animals}

A pair of mice heterozygous for the $\operatorname{src}^{\text {tm1sor }}$ targeted mutation were purchased from the Jackson Laboratory (Bar Harbor, Maine, USA) and maintained in the animal facility at the Central Research Institute of the Electric Power Industry. After weaning, the homozygous descendants ( $c$-src KO mice) were fed a soft diet comprising a mixture of powdered diet (Nippon No-san, Yokohama) and pudding (Meito, Kyodo-Nyugyo, Tokyo) with free access to water. Wild-type and heterozygous mice were grown in separate cages under a regular diet. At least two each of neonatal, 0-, 6-, 17-day-old, 3.5, 5, 14-week-old, and 4, 7, 12, 18, and 21-month-old $c$-src homozygous (-/-) mice and their wild type $(+/+)$ and/or heterozygous $(-/+)$ counterparts were examined in this study.

Unlike in a previous report (Amling et al.), the $c$-src deficient mice of both sexes survived well beyond 12 months, and no incidence of death by suffocation was encountered up to 21 months after birth.

\section{Tissue preparation}

Under anesthesia with ether inhalation and an intraperitoneal injection of $4 \%$ chloral hydrate solution ( $400 \mathrm{mg} / \mathrm{kg}$ body weight), animals including neonates were fixed by vascular perfusion via the left ventricle with a $4 \%$ paraformaldehyde (PFA) solution in a $0.1 \mathrm{M}$ phosphate buffer (pH 7.4). Fixed animals were further immersed in the same fixative for more than $12 \mathrm{~h}$ at 
$4{ }^{\circ} \mathrm{C}$. After the completion of fixation, the heads were cut in halves along the midsagittal plane, and $\mathrm{X}$-ray images were taken using a cabinet type soft $X$-ray imaging system, SOFRON SRO-M50 (Sofron Co. Ltd, Tokyo). Maxillae and mandibles were excised and processed for embedding either in paraffin or Technovit 7100 (Kulzer, Wehrheim, Germany), a water miscible resin. Samples of neonates and day 6 animals were embedded in Technovit 7100 without decalcification while those of older animals were generally decalcified with neutralized $10 \%$ ethylen ediaminetetraacetic acid (EDTA; pH 7.4) at $4{ }^{\circ} \mathrm{C}$ prior to dehydration and embedding.

\section{Histological and histochemical staining}

Serial bucco-lingual sections of the paraffin-embedded specimens $(4 \mu \mathrm{m})$ and Technovit-embedded specimens (2 $\mu \mathrm{m})$ were respectively processed either for hematoxylin/ eosin staining, azan staining, periostin immunostaining, or for enzyme histochemistry of tartrate-resistant acid phosphatase (TRAP) activity in the growing jaw bones and tooth germs.

\section{TRAP enzyme histochemistry}

Two- $\mu \mathrm{m}$-thick Technovit sections of the upper and lower jaws were adhered to glass slides at room temperature and incubated for the histochemical demonstration of TRAP activity by the Azo dye method (Burstone, 1961) for $1 \mathrm{~h}$ at $37{ }^{\circ} \mathrm{C}$ in a medium comprising $0.8 \%$ naphthol $\mathrm{AS}-\mathrm{MX}$ phosphate as substrate and $0.7 \%$ fast red violet LB salt as capture agent in a $0.1 \mathrm{M}$ acetic buffer ( $\mathrm{pH} 5.2$ ). Fifty $\mathrm{mM}$ $\mathrm{L}-(+)$ tartaric acid was added to the incubation medium, and the $\mathrm{pH}$ was adjusted to a final value of 5.2 with $1 \mathrm{~N} \mathrm{NaOH}$. The incubated sections were lightly counterstained with methyl green or methylene blue prior to observation.

\section{Immunolocalization of periostin}

Rabbit anti-mouse periostin antibody (Horiuchi et al., 1999) at a dilution of 1:3000 was utilized as the primary antibody. Diluted normal rabbit serum at the same concentration was used for a negative control in place of the primary antibodies. De-waxed paraffin sections were treated with $0.3 \% \mathrm{H}_{2} \mathrm{O}_{2}$ in absolute methanol followed by $2 \%$ normal goat serum in PBS to avoid non-specific precipitation of the antibodies. The sections were then incubated for $1 \mathrm{~h}$ at room temperature with the primary antibody diluted in PBS, followed by incubation with biotinylated goat anti-rabbit $\operatorname{IgG}(1: 200)$ as the secondary antibody. The immunopositive sites were decorated with HRP-conjugated streptavidine using the ABC kit (Vector, Burlingame, CA, USA) and visualized by incubating with
3,3' -diaminobenzidine tetrahydrochloride (DAB) solution. The sections were counterstained with methyl green.

\section{Transmission electron microscopy}

Some PFA-fixed specimens were further fixed by immersion in $2.5 \%$ glutaraldehyde in a $0.1 \mathrm{M}$ cacodylate buffer ( $\mathrm{pH} 7.3$ ) for $2 \mathrm{~h}$ at $4{ }^{\circ} \mathrm{C}$, followed by routine processing for epoxy resin embedding with or without prior decalcification by $10 \%$ EDTA. Ultrathin sections were doubly stained with uranyl acetate and lead citrate and examined by a Hitachi $\mathrm{H}-7100$ transmission electron microscope (Hitachi Ltd., Tokyo) at an acceleration voltage of $75 \mathrm{kV}$.

\section{Preparation of dry bone samples}

The PFA-fixed upper and lower jaws of a 14-week-old homozygous animal were treated with $5 \% \mathrm{KOH}$ solution for 3 days at $37^{\circ} \mathrm{C}$ and cleared of all soft tissue elements. The bone samples thus prepared were rinsed, air dried, and examined under a dissection microscope.

\section{Results}

\section{Radiographic surveillance of tooth development in c-src deficient mice}

In the neonatal animals of both wild type (WT) and homozygous alleles of $c$-src disruption, the 1 st and the 2 nd molars in upper and lower jaws were in the bell stage of development. At postnatal day 6, they were in the mid or early stage of crown formation, and no difference was noted in their developmental or structural features between WT and homozygous animals (cf. Fig. 1a, b and $1 \mathrm{i}, \mathrm{j}$ ). In contrast, apical growth (elongation) of the upper and lower incisors in homozygous mice was severely hindered already in the neonatal animals, and the incisors appeared to terminate their longitudinal growth in 3 to 5 weeks of postnatal development, at least in soft X-ray images (Fig. 1i-n).

In the 3rd week and later stages of development, the influence of $c$-src deficiency became prominent also in the molar teeth. In day 17 WT mice, the 1 st and the 2 nd molars were in the mid stage of root formation while the 3rd molar was near completion of crown formation (Fig. 1c, d). In $c$-src deficient mice, however, root formation of the 1 st and the 2 nd molars was substantially delayed in both the upper and lower jaws, and no sign of mineralization was depicted in the $3 \mathrm{rd}$ molar at this 

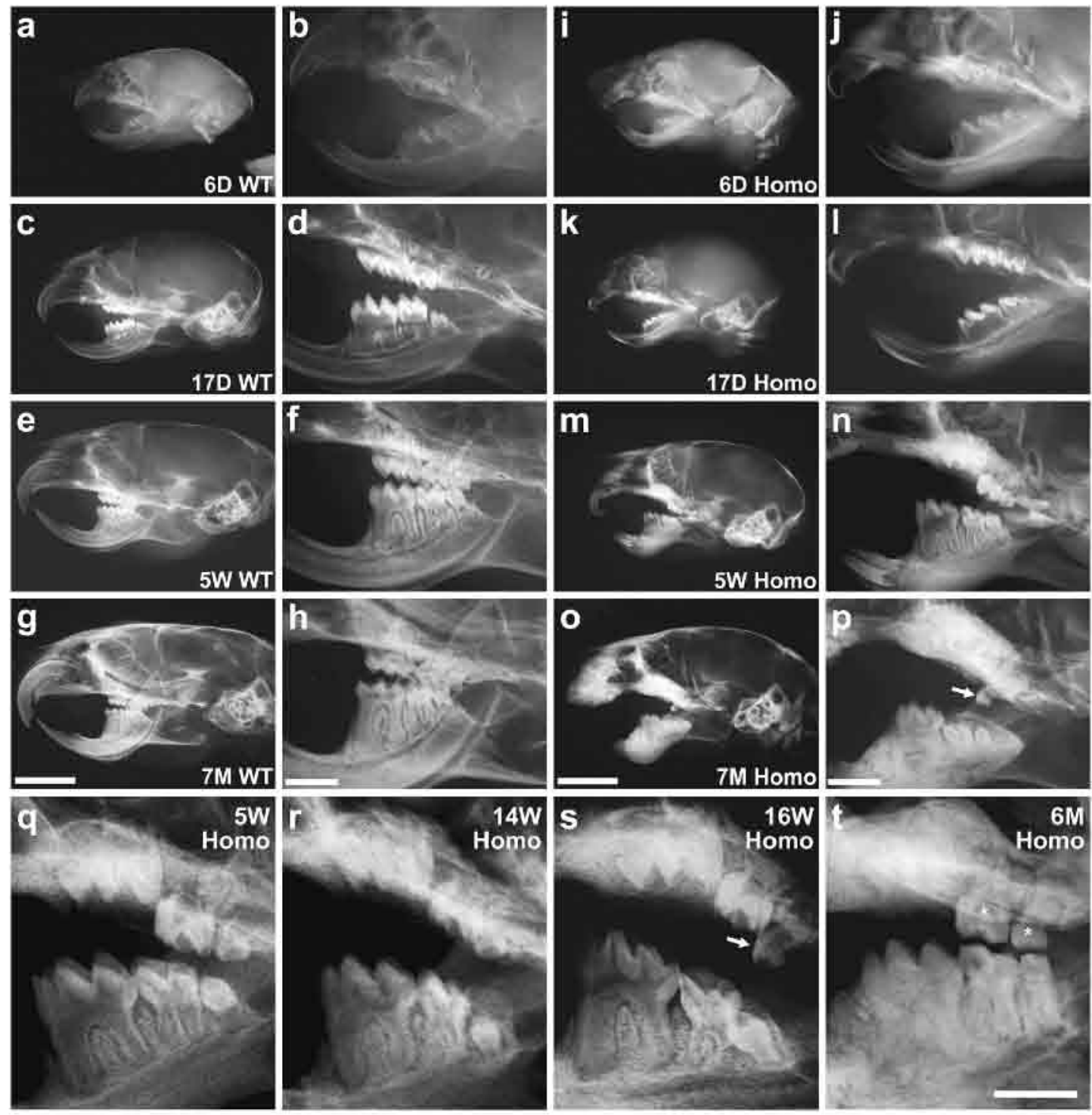

Fig. 1. Soft X-ray images of the mouse skull showing the effect of $c$-src deficiency on postnatal development of molar teeth. a-h: Lateral views of the skull and the molar regions of wild type (WT) mice at postnatal day 6 (a, b), day $17(\mathbf{c}, \mathbf{d})$, 5th week $(\mathbf{e}, \mathbf{f})$ and 7 th month $(\mathbf{g}, \mathbf{h})$. i-p: Lateral views of the skull and the molar regions of homozygous mice at postnatal day $6(\mathbf{i}, \mathbf{j})$, day $17(\mathbf{k}, \mathbf{l}), 5$ th week $(\mathbf{m}, \mathbf{n})$ and 7 th month $(\mathbf{o}, \mathbf{p})$. q-t: Enlarged views of molar regions of homozygous mice showing various patterns of disturbance of the molar tooth eruption. Practically no difference is noted in molar tooth development between wild type and homozygous animals at post natal day 6, but a considerable delay in tooth development becomes evident in the homozygous mouse in day 17 animals (cf. d and I). By the 5th week, molar teeth nevertheless fully grow in the homozygous mouse except for the upper 1st molar that shows defective roots and remains deep in the alveolar socket (m, n). Generally, the upper 1st molar is fully impacted, whereas the lower 1st molar is fully erupted into the oral cavity. The upper and lower 2 nd and 3rd molars show various degree of disturbance of eruption. Arrows in $\mathbf{p}$ and $\mathbf{s}$ indicate fully erupted upper 3rd molars despite a full or partial impaction of the upper 1 st and 2 nd molars. Asterisks in $\mathbf{t}$ indicate the 2nd and 3rd molars showing distinct occlusal wear suggestive of functional occlusion with these teeth. Left hand side is rostral in all figures. Bars $=5 \mathrm{~mm}(\mathrm{a}, \mathrm{c}, \mathrm{e}, \mathrm{g}, \mathrm{i}, \mathrm{k}, \mathrm{m}, \mathrm{o}), 2 \mathrm{~mm}(\mathrm{~b}, \mathrm{~d}, \mathrm{f}, \mathrm{h}, \mathrm{j}, 1, \mathrm{n}, \mathrm{p}), 1 \mathrm{~mm}(\mathrm{q}-\mathrm{t})$ 
Fig. 2. Jaw bones of a 14-week-old $c$-src deficient mouse. a: Buccal view of maxilla. Arrow indicates the tip of the incisor. $\mathbf{b}$ : Occlusal view of the molar region indicated by a white bracket in (a). Three depressions corresponding to $1 \mathrm{st}, 2 \mathrm{nd}$, and $3 \mathrm{rd}$ molars (M1, M2, M3) are evident. Tooth crowns of all molars remain deep in the alveolar socket in this case. Note that the apical opening of the alveolar socket of molars is smallest for the upper 1st molar (M1). c: Buccal view of the mandible. Arrow indicates the fully erupted crown of the 1 st molar and partially emerging proximal cusp of the 2 nd molar. d: Lingual aspect of the lower molar region. The cement-enamel junction of the lower 1st molar (M1) is above the level of the alveolar crest and hence fully erupted, but pointed cusps of this tooth indicate the absence of any functional occlusal contact. Bars $=2 \mathrm{~mm}$ (a,
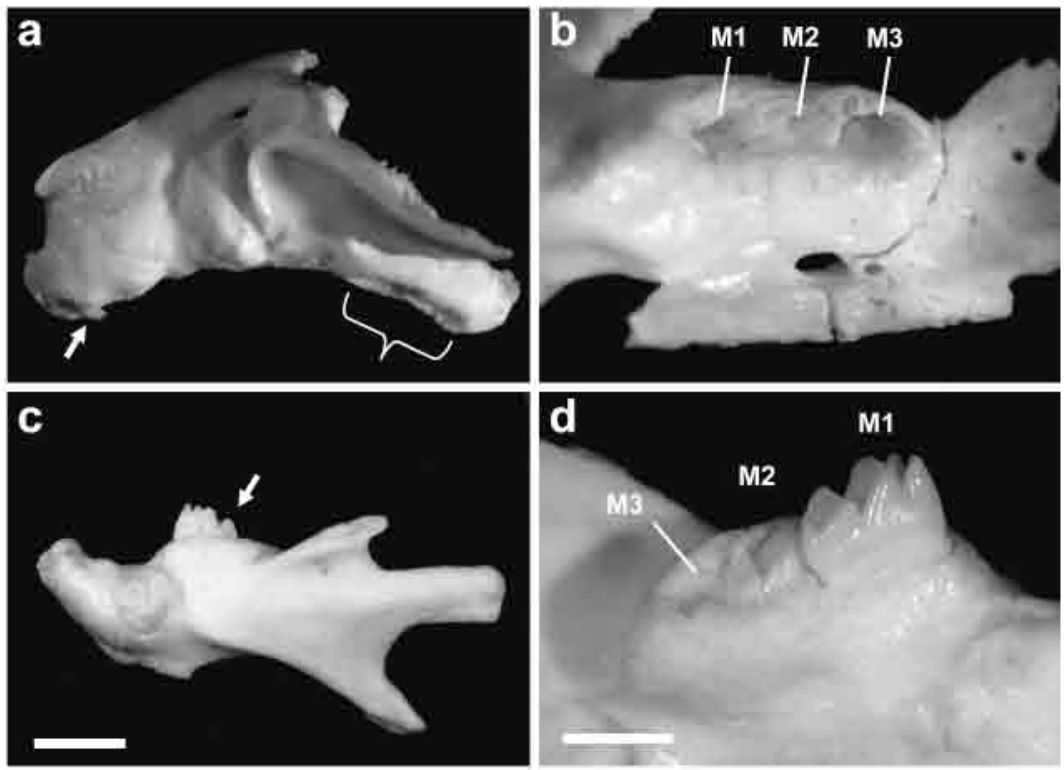
c), $1 \mathrm{~mm}$ (b, d)

Table 1. A summary of the state of eruption of molar teeth based on soft X-ray images of the upper and lower jaws of ten 14-week-old $c$-src deficient mice. A considerable variation in the magnitude of disturbance of tooth eruption is noted among the types of molars.

\begin{tabular}{clccc}
\hline $\mathrm{n}=20$ & & 1st molar & 2nd molar & 3rd molar \\
\hline \multirow{3}{*}{ Upper } & Full eruption & 0 & 1 & 6 \\
molars & Half eruption & 0 & 0 & 0 \\
& Even level & 0 & 8 & 6 \\
& Half impaction & 0 & 0 & 0 \\
& Full impaction & 20 & 11 & 8 \\
\hline \multirow{2}{*}{ Lower } & Full eruption & 17 & 4 & 1 \\
molars & Half eruption & 1 & 7 & 1 \\
& Even level & 2 & 5 & 1 \\
& Half impaction & 0 & 3 & 16 \\
\hline
\end{tabular}

stage of development (cf. Fig. 1d and 11). In WT animals, all molars were in full eruption and attained occlusal contact in the 5 th week of development (Fig. 1e, f). In $c$ src deficient mice, the root development of molars except that of the upper 1st molar appeared to catch up with that of the molars of WT animals by 5 weeks. In particular, the lower 1st molar had well developed roots and fully erupted into the oral cavity in 5-week-old animals in most of the animals examined. In contrast to the lower 1st molar, root formation and eruption of the upper 1st molar was severely disturbed and the tooth crown remained deep in the alveolar socket throughout development in all animals examined (Fig. 1m-t, 2). In the case of the 2nd and 3rd molars, however, eruption profiles of these teeth in the individual animals varied from full eruption to near full impaction at this and later stages of development 


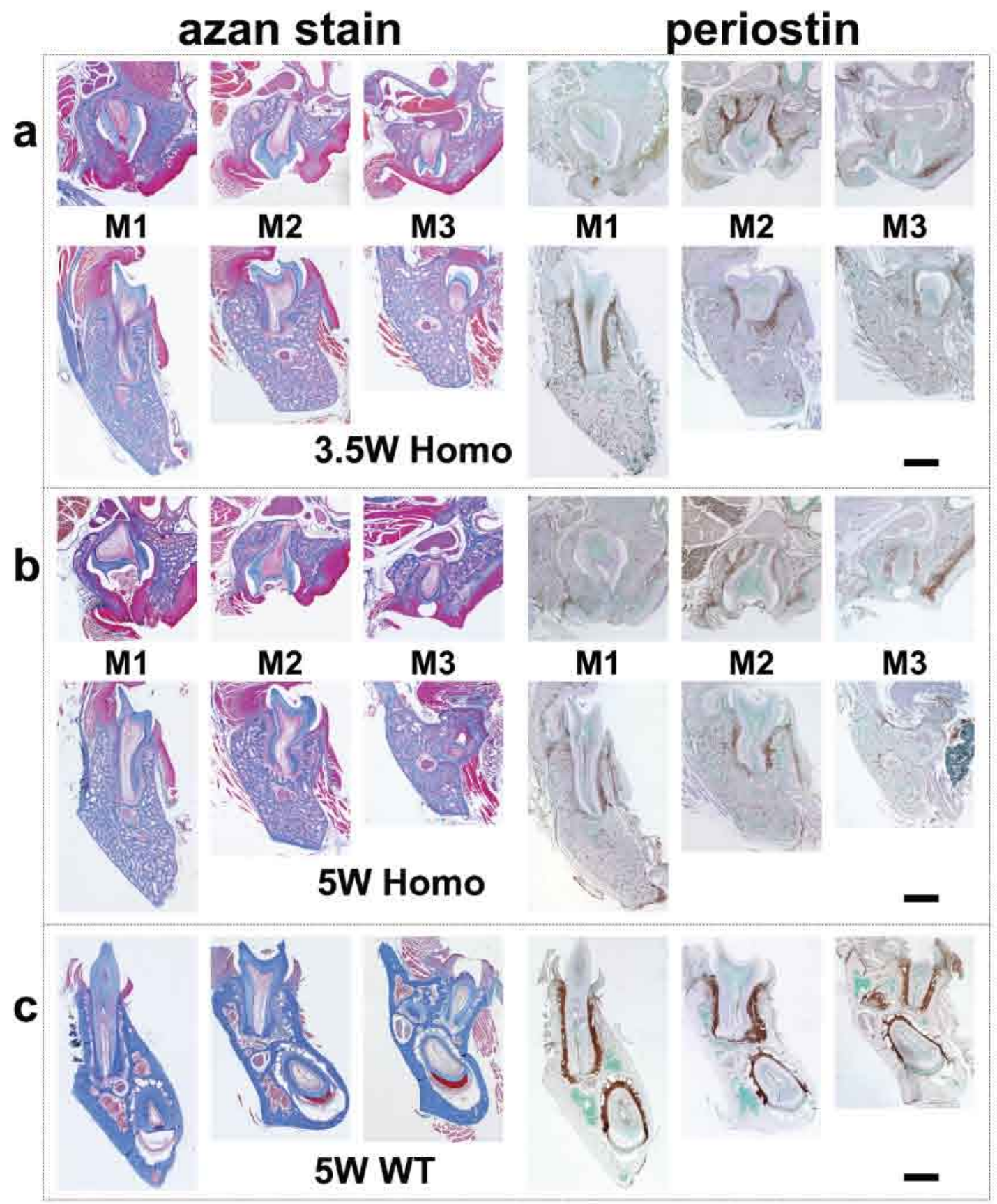

Fig. 3. Structural features and immunohistochemical localization of periostin in the bucco-lingual sections of the molars of $c$-src deficient mice at 3.5 weeks (a) and 5 weeks (b). All molars except the upper 1st molars show well developed roots and periostin-positive periodontal ligament (a, b) comparable to those in wild type controls (c). The molar tooth crowns of $c$-src deficient mice are generally above the level of the alveolar crest but, in most cases, partially covered with a thick fold of buccal mucosa. In contrast, the upper 1st molars have highly defective roots and remain deep in the alveolar socket, which only have a narrow opening in the eruption pathway. Immunoreaction of periostin in the periodontal ligament of the molars of homozygous mice is stronger at postnatal 3.5 weeks than at 5 weeks, but far less intense relative to that shown in the periodontal ligament of a 5-week-old wild type animal. Bars $=500 \mu \mathrm{m}$ 


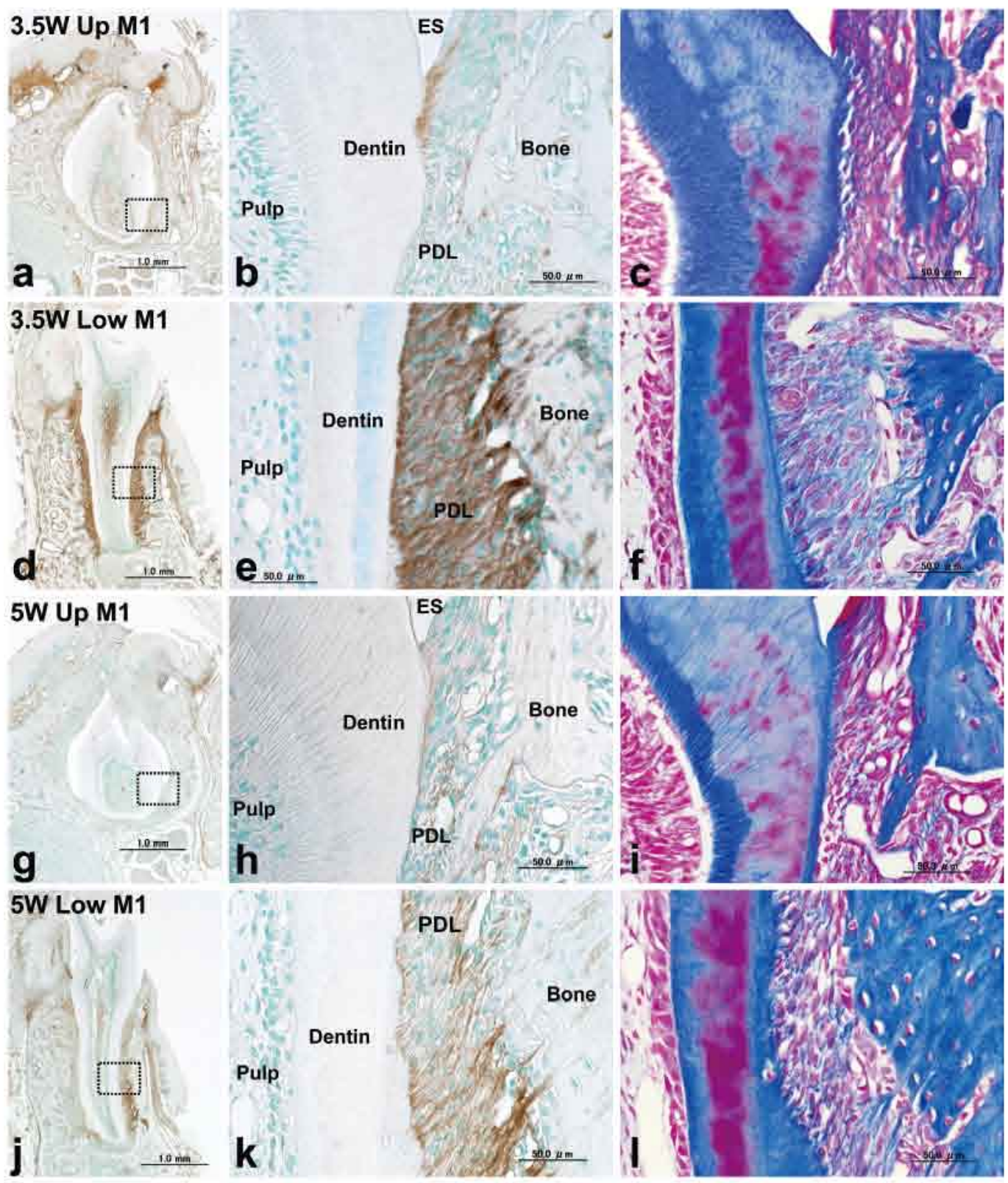

Fig. 4. Structural and immunohistochemical features of periodontal ligament of 3.5-week-old (a-f) and 5week-old (g-I) c-src deficient mice: a comparison between the upper and lower 1st molars. Boxed areas in $\mathbf{a}, \mathbf{d}, \mathbf{g}, \mathbf{j}$, are enlarged in $\mathbf{b}, \mathbf{e}, \mathbf{h}, \mathbf{k}$ (periostin reactions) and $\mathbf{c}, \mathbf{f}, \mathbf{i}, \mathbf{I}$ (azan staining). The occlusal plane is arranged upward. In the upper 1st molars, collagen fibers in the narrow periodontal ligament are randomly arranged $(\mathbf{c}, \mathbf{i})$ and do not show significant immunoreactions of periostin at either 3.5 weeks $(\mathbf{a}, \mathbf{b})$ or 5 weeks $(\mathbf{g}, \mathbf{h})$. In the lower 1st molars, periodontal collagen fibers are regularly arranged in thick bundles extending over from the cementum to the neighboring alveolar bone at both 3.5 weeks (f) and 5 weeks (I). Intensity of periostin immunoreactions in the periodontal ligament is strongly positive at 3.5 weeks (d, e) but decrease drastically by the 5 th week $(\mathbf{j}, \mathbf{k})$. Bars $=1 \mathrm{~mm}(\mathrm{a}, \mathrm{d}, \mathrm{g}, \mathrm{j}), 500 \mu \mathrm{m}(\mathrm{b}, \mathrm{c}, \mathrm{e}, \mathrm{f}, \mathrm{h}, \mathrm{i}, \mathrm{k}, \mathrm{l})$ 


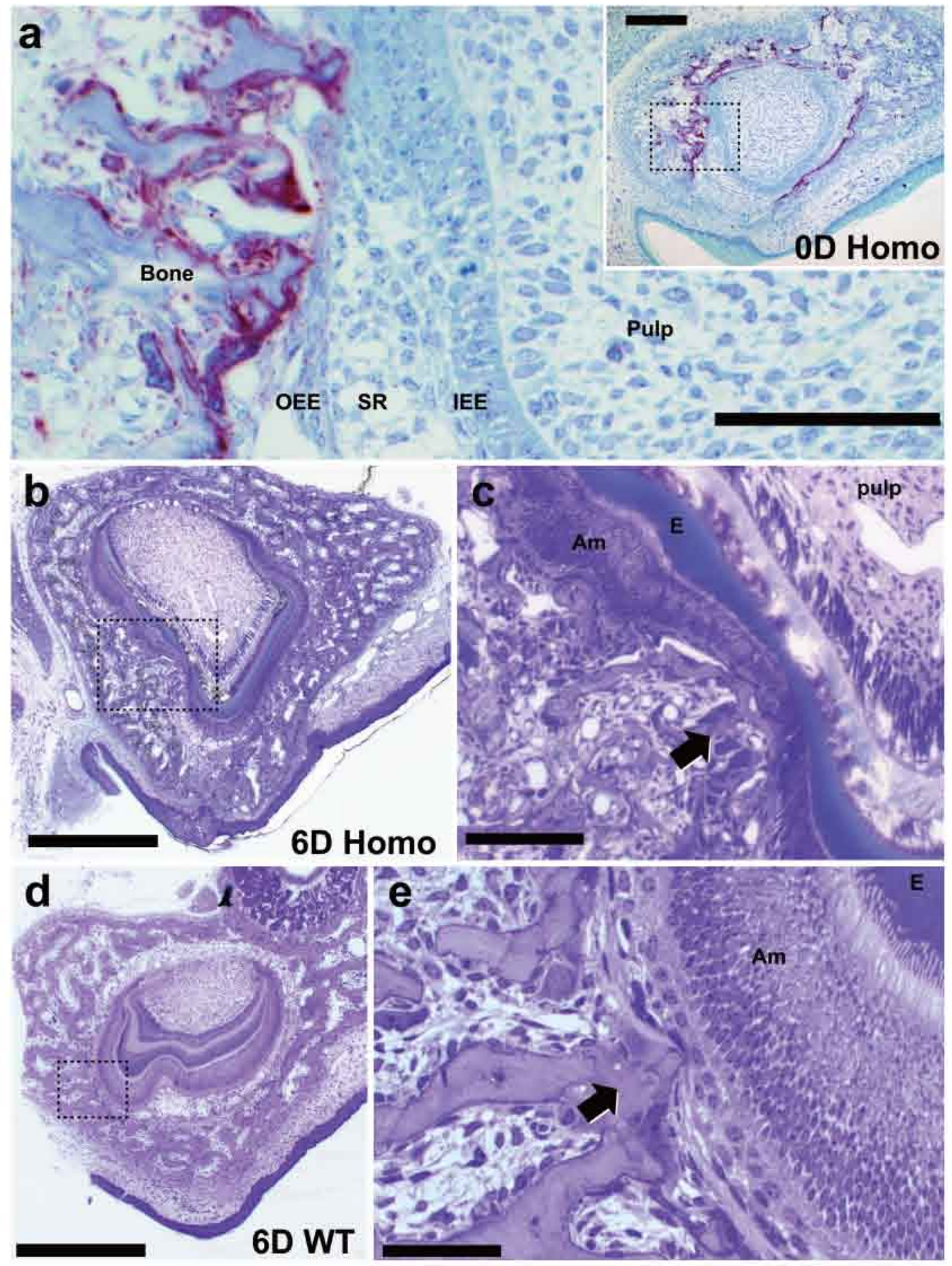

Fig. 5. Early development of the upper 1 st molar tooth germ viewed in bucco-lingual sections. a: TRAP reactions in the upper 1st molar of a newborn homozygous mouse. Despite numerous TRAP positive osteoclasts located around the alveolar socket (inset), the trabecular bone is often in contact with or lightly indenting the enamel organ. b: Proximal portion of the upper 1st molar in a 6-day-old homozygous mouse. c: (Continued on the next page $\nearrow$ ) 

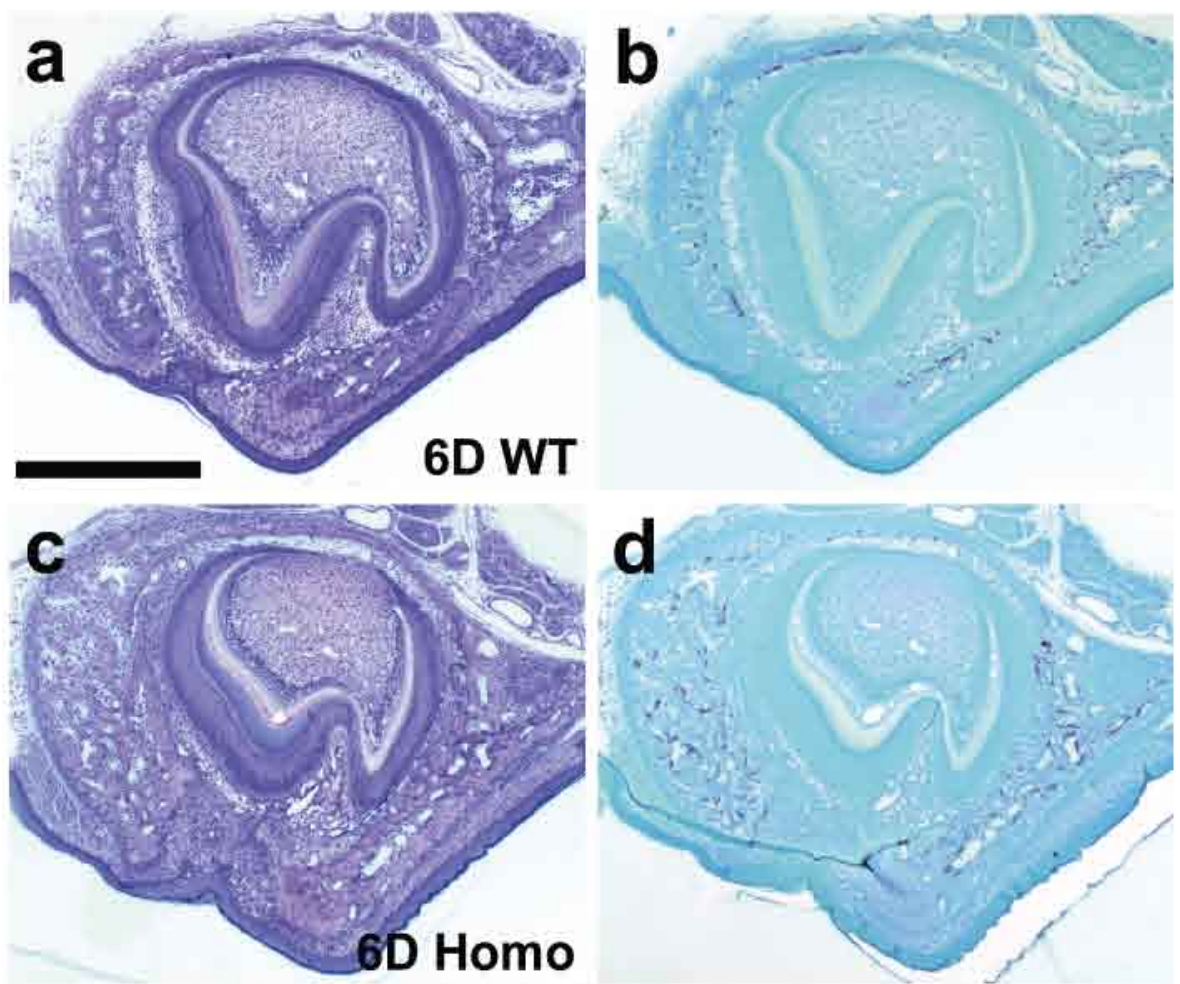

Fig. 6. Features of the day 6 upper 2nd molars and osteoclast function. Molar tooth germs of both wild type (a, b) and homozygous (c, d) mice show similar structural features and have similarly narrow openings of their eruption pathway. TRAP positive cells are arranged in a line on the inner surface of the alveolar socket in wild type animals (b), but these cells are spread out throughout the alveolar bone in homozygous mice (d). Transmission electron microscopy shows internalization of bone matrix by the osteoclast without a ruffled border (arrows in e). Bars $=500 \mu \mathrm{m}(\mathrm{a}-\mathrm{d}), 1 \mu \mathrm{m}(\mathrm{e})$

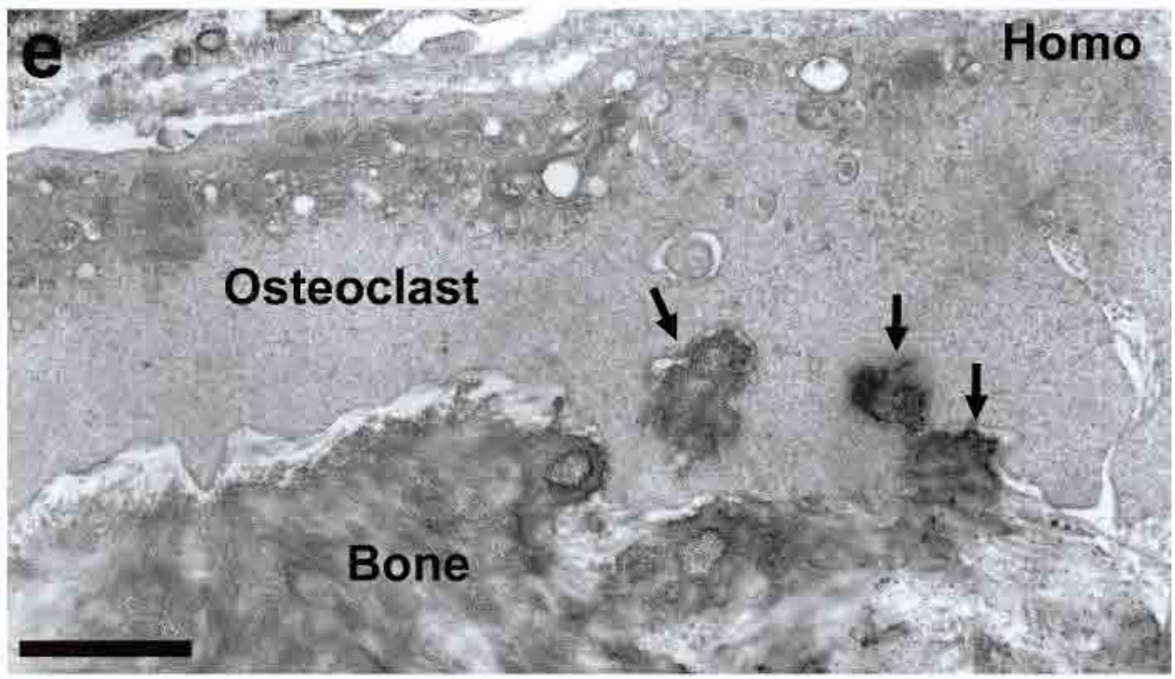

Fig. 5. c: Enlargement of a boxed area in $\mathbf{b}$. Secretory ameloblasts and enamel layers are compressed and severely deformed by the trabecular bone (arrow). d: Proximal portion of the upper 1st molar in a 6-day-old heterozygous mouse. e: Enlargement of a boxed area in $\mathbf{d}$ showing a punctuate compression of the enamel organ with the trabecular bone (arrow). toluidine blue staining (b-e) OEE: outer enamel epithelium, SR: stellate reticulum, IEE: inner enamel epithelium, Am: ameloblast, E: enamel. Bars $=50 \mu \mathrm{m}(\mathrm{e}), 100 \mu \mathrm{m}(\mathrm{a}, \mathrm{c}), 200 \mu \mathrm{m}$ (a inset), $500 \mu \mathrm{m}(\mathrm{b}, \mathrm{d})$ 


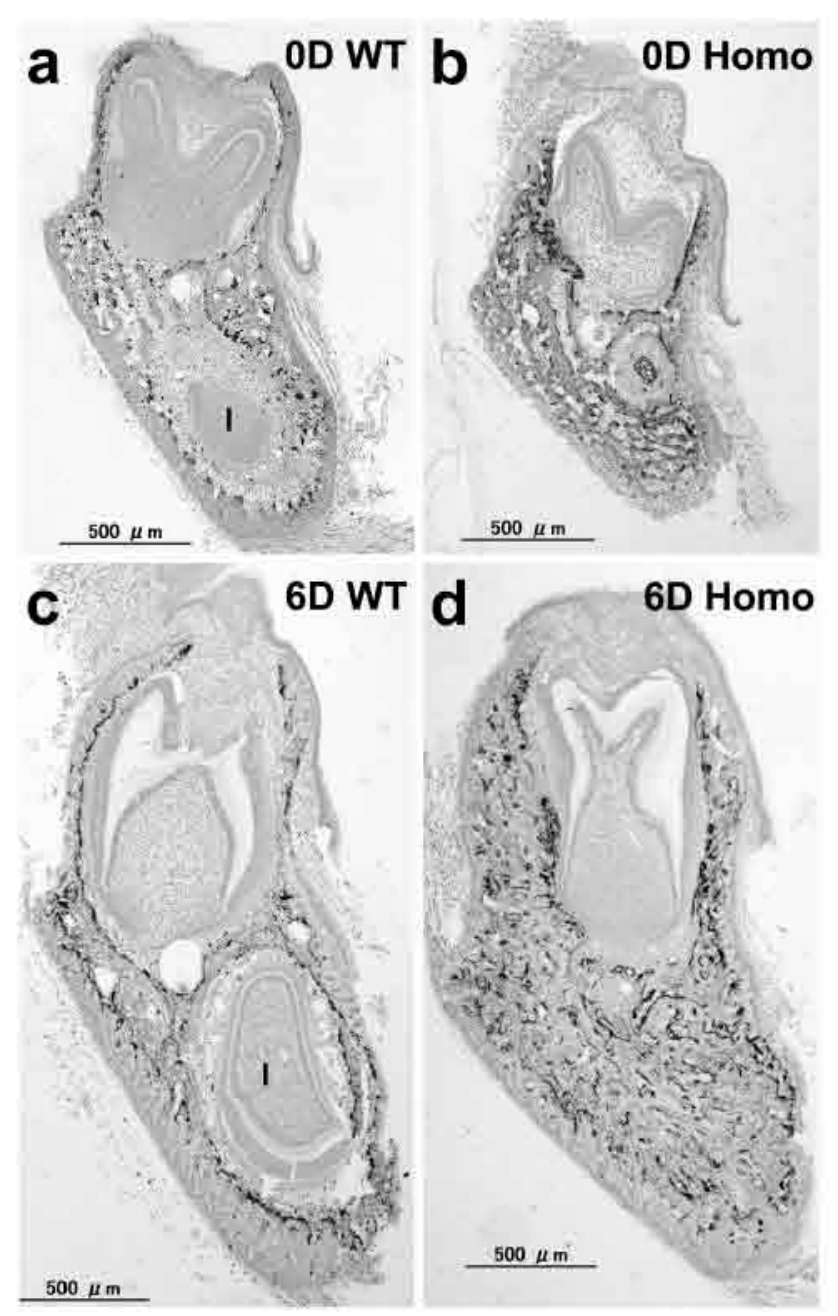

Fig. 7. TRAP reactions and eruption pathway of the lower 1st molars at postnatal day 0 and day 6 viewed in bucco-lingual sections. Unlike in the upper jaws, the opening of the eruption pathway of the lower 1st molar is wide open in both wild type (a, c) and homozygous (b, d) mice. In homozygous mice, it is already wide enough for the tooth crown to pass through at day 0. Localization of TRAP positive osteoclasts in wild type and homozygous mice is comparable to that in the upper jaws as shown in Figure 6a, b. I: incisor. Bars $=500 \mu \mathrm{m}$

in both upper and lower jaws (Fig. 1m-t, 2). Table 1 summarizes the eruption profiles of the molars in the 14 week old $c$-src deficient mice $(\mathrm{n}=20)$ based on the relative spatial relation of the vertical level of the tooth crown with that of the alveolar crest as shown in the soft X-ray images.
Generally, there was no sign of occlusal contact of the molar teeth in $c$-src deficient mice, and in the animals older than 6 months of age, the periodontal space of the molars became very narrow and obscured in x-ray images (Fig. 1o, p). Unexpectedly, however, in one case of a 6 month old homozygous mouse, we encountered apparent occlusal wear in the 2 nd and 3 rd molars, implicating functional occlusion of the respective teeth. The periodontal space of these functional teeth retained $\mathrm{x}$-ray translucency, whereas that of the lower 1st molar without occlusion was very obscured (Fig. 1t).

\section{Structural and immunohistochemical features of molars and periodontal ligament of c-src deficient mice}

In bucco-lingual sections of the 3.5 week old and 5 week old $c$-src deficient mice, the lower 1 st molar and the 2 nd and the 3rd molars of both jaws showed well developed roots and periodontal ligaments comparable to those of equally aged WT mice (Fig. 3). At least a portion of the crown of these teeth was above the level of the alveolar crest and, in the case of the lower 1st molar, emerged into the oral cavity in most incidences. Unlike in the WT animals, however, buccal cusps of most of the erupted molars in homozygous mice were covered by a thick fold of buccal mucosa, implicating no direct occlusal contact of these molars. As shown in the X-ray images of homozygous mice, the upper 1 st molar remained deep in the alveolar socket, and its eruption pathway was extremely narrow and practically closed throughout development (Fig. 3a, b).

In 3.5-week-old homozygous mice, distinct immunoreactions for periostin were localized in the periodontal ligament of the molars except for the upper $1 \mathrm{st}$ molar, which showed poor root development (Fig. 3a). Periostin reactions in the periodontal ligament of the molars of homozygous mice were generally less intense than those in the normally functioning molars of the agematched WT mice. Moreover, periostin reactions in the periodontal ligament of homozygous mice became far less intense during 3.5 weeks to 5 weeks of postnatal development (cf. Fig. 3a, b, c).

A comparison between histology and periostin immunoreactions in the periodontal ligament of the molars of 3.5-week- and 5-week-old mice revealed a parallel correlation of periostin reactions in the periodontal ligament with the development of principal fibers in the respective periodontal ligament (cf. Fig. $4 a-f$ and $4 j-1$ ). In the upper 1 st molars, the narrow periodontal space only contained randomly arranged fibrous elements showing very little immunoreactivity for periostin (Fig. $4 a-c, g-i$ ). 


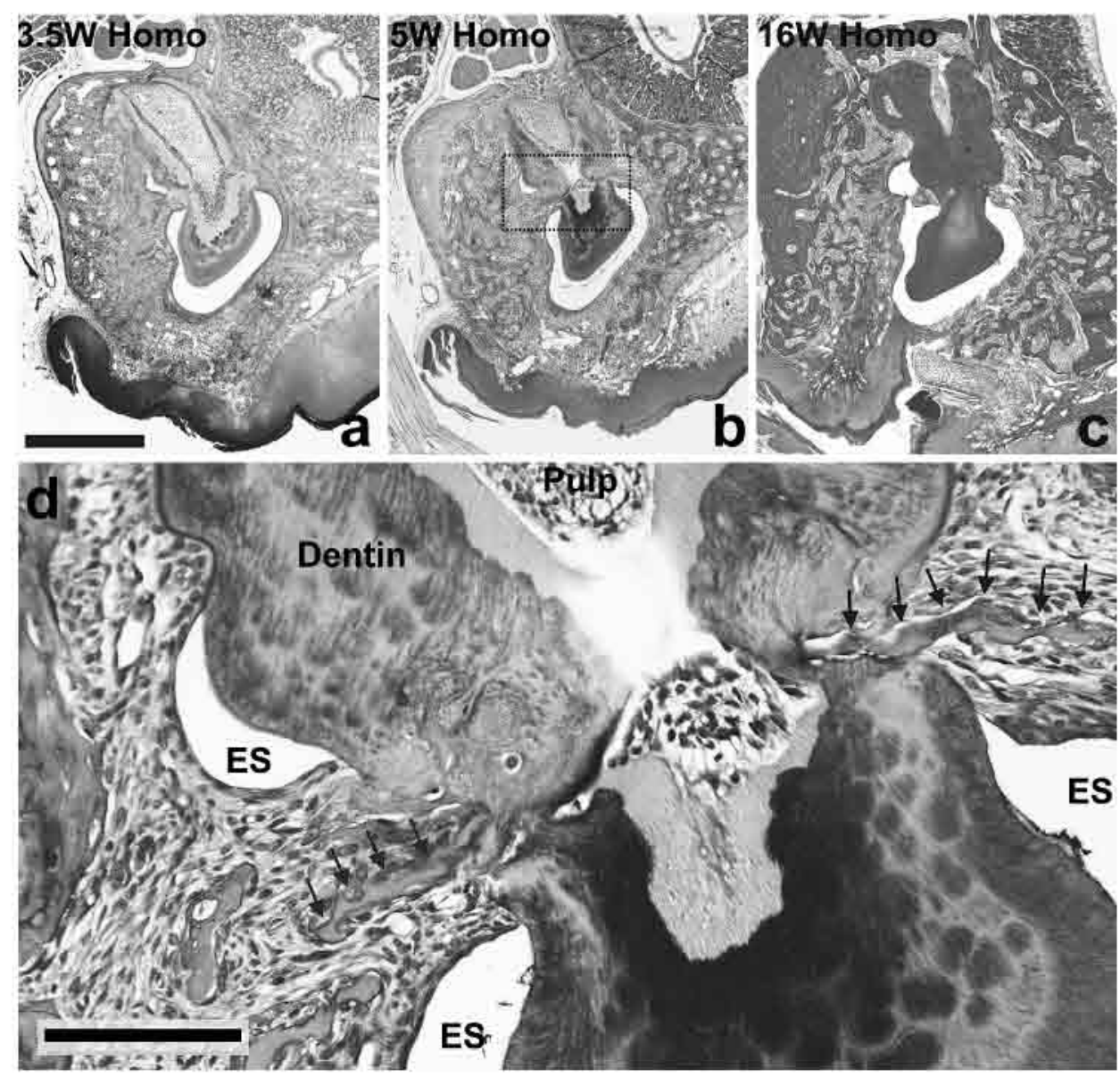

Fig. 8. Disturbed crown formation in the upper 1st molar of $c$-src deficient mice. Bucco-lingual sections of the upper 1 st molars through the mesial root show characteristic indentations of the tooth crown at the cervical region in 3.5-week-old (a), 5-week-old (b, d) and 16-week-old (c) mice. At high magnification, the deep indentation is stuck by bone spicules (arrows). Toluidine blue staining. ES: enamel space. Bars $=500 \mu \mathrm{m}(\mathrm{a}, \mathrm{b}, \mathrm{c}), 100 \mu \mathrm{m}(\mathrm{d})$

\section{Spatial relationship between growing molars and surrounding bones}

In order to clarify possible causes for the tooth-type specific disturbances in eruption and root development in $c$-src deficient mice, histological features and the distribution of TRAP positive cells were examined in the bucco-lingual sections of the 1 st and 2 nd molars at days 0 and 6 of development.

\section{Upper 1st molars}

In newborn homozygous mice, the tooth germ of the upper 1 st molar was in the bell stage of development, being surrounded by the trabecular bones on which numerous TRAP positive cells were located. In the buccal aspect of the tooth germ, portions of the trabecular bones were often in contact with the enamel organ (Fig. 5a).

In day 6 animals, the upper 1st molar was in the mid stage of crown formation in both WT and homozygous animals. In $c$-src deficient mice, a portion of the buccal aspect of the enamel organ of the upper 1st molar was often compressed with bone trabeculae as exhibited in newborn animals. The ameloblasts in such regions were severely deformed, and the enamel layer was much thinner than in the neighboring regions (Fig. 5b, arrow in 5c). The TRAP positive cells in the alveolar bone in 


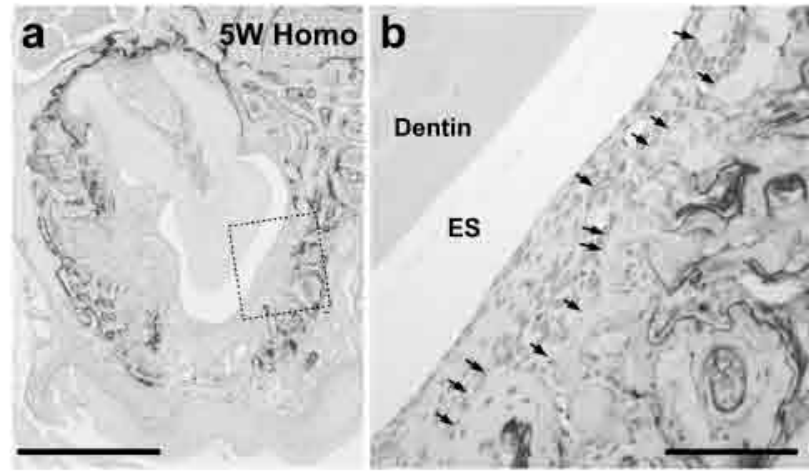

Fig. 9. a: Histochemical localization of TRAP activity in the upper 1st molar region of a 5-week-old homozygous mouse. b: Enlarged view of the boxed area in a indicates the absence of TRAP positive cells from the inner aspect of the alveolar socket (arrows). Bars $=500 \mu \mathrm{m}$ (a), $100 \mu \mathrm{m}$ (b)

homozygous mice appeared more abundant than in WT animals. Of note, however, is the finding that while the TRAP positive cells in WT animals were concentrated in the inner aspect of the alveolar wall, those in homozygous mice were dispersed throughout a dense meshwork of trabecular bones, being rather sparse in the inner aspect of the alveolar socket, and generally absent at the tip of bone spicules practically in contact with the enamel organ (data not shown).

In 6-day-old WT animals, the distance between the enamel organ and the apposing bone was much closer than in the other types of molars despite the distribution of TRAP positive cells along the inner alveolar surface. Notably, there was an incidence of slight compression of the enamel organ of the upper 1 st molar by a bone spicule as shown in Figure 5d,e.

\section{Upper 2 nd molars}

The upper 2 nd molar was in early stage of crown formation at day 6 of development, being surrounded by the alveolar bone, which had a narrow opening in the eruption pathway in both WT and homozygous mice (Fig. $6 \mathrm{a}-\mathrm{d})$. The population and distribution of TRAP positive cells in the alveolar bone were same as described for the upper 1st molar (Fig. 6b, d). Although the osteoclasts in $c$-src deficient mice lacked a ruffled border, apparent internalization of a chunk of bone matrix by these cells was confirmed in our transmission electron microscopic observations (Fig. 6e), indicating bone resorbing activity in these cells.

Lower 1st and 2nd molars

The distribution patterns of TRAP positive cells in the alveolar bone surrounding the lower 1st molars in WT and homozygous mice were identical to those described for the upper molar regions. However, in contrast to the upper molars, the eruption pathways for the lower 1st molars in both WT and homozygous animals were much wider at days 0 and 6 of development (Fig. 7). The distribution patterns of TRAP positive cells and the size of the eruption pathways were similar for the lower 2 nd molars at these same days of development (data not shown).

\section{Disturbed eruption of the upper 1st molar by trabecular bone spicules}

The upper 1st molars of homozygous mice, deeply impacted in the alveolar socket in 3.5-, 5-, and 16-weekold animals, displayed structural features characteristic to all affected animals when viewed in bucco-lingual sections through the mesial portion of the tooth crown (Fig. 8). As shown in Figure 8a, the cervical portion of the crown of the upper 1 st molar was highly constricted at 3.5 weeks and did not make any vertical movement through the later stages of development (Fig. 8b,c). In most cases, constricted portions of the tooth crown were deeply indented with bone spicules and lacked enamel layers (Fig. 8d). Ankylosis was noted in the apical portion of the root in these teeth. TRAP staining of the sections of a 5-week-old mouse indicated the absence of osteoclasts along the inner aspect of the alveolar socket as well as the surface of the bone spicules indenting the tooth crown (Fig. 9).

\section{Transient dentin hypomineralization in developing molars of c-src deficient mice}

The total thickness of dentin and predentin in the 1st molars of WT and homozygous animals was comparable at least up to the 5 th week of postnatal development. A widening of predentin layers was noted in the molars of $c$ src deficient mice at the sites of mantle dentin formation in both crown and root regions (cf. Fig. 10a and b). Subsequently, globular mineralization of dentin started in the widened predentin layers, leaving a nonmineralized matrix of interglobular dentin (Fig. 10c). The width of predentin combined with the areas of interglobular dentin became most conspicuous at 3.5 weeks (Fig. $8 \mathrm{~d}$ and 10d), rapidly decreased thereafter, and became identical to that of WT molars by the 5th week of development. 


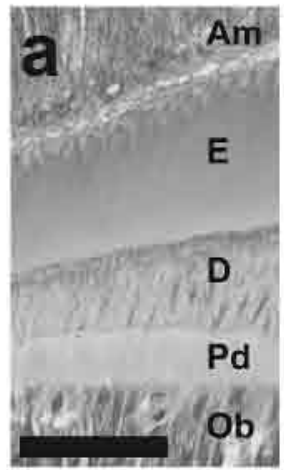

6D
WT

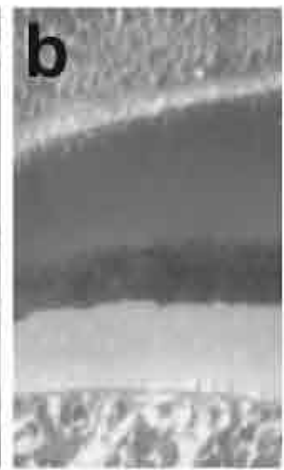

6D

Homo

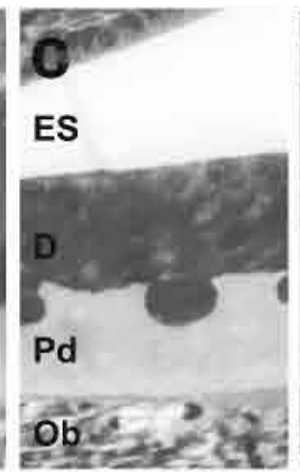

17D

Homo

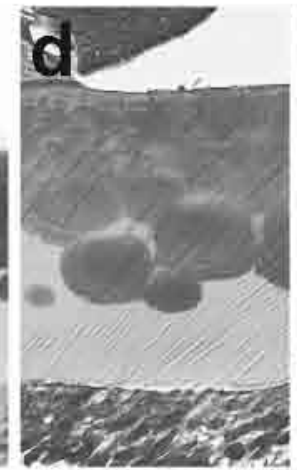

$3.5 \mathrm{~W}$ Homo

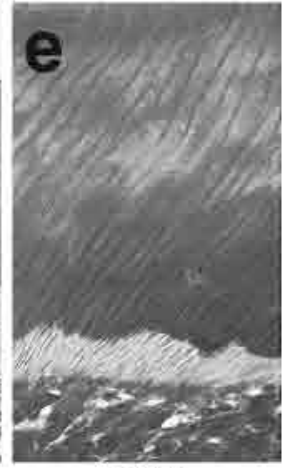

$5 \mathrm{~W}$

Fig. 10. Transient hypomineralization of dentin in $c$-src deficient mice.

At postnatal day 6 , the thickness of predentin layer is wider in the molars of homozygous mice (b) than that of wild type mice (a) but the total thickness of dentin and predentin is identical in both animals. The globular mineralization of dentin becomes conspicuous at day 17 and 3.5 weeks in homozygous mice leaving nonmineralized matrix of interglobular dentin $(\mathbf{c}, \mathbf{d})$. Thickness of predentin layer rapidly decreases until the 5th week and becomes identical to that in the wild type animal (e). Am: ameloblast, E: enamel, D: dentin, Pd: predentin, Ob: odontoblast, ES: enamel Space. Bar $=50 \mu \mathrm{m}$

\section{Discussion}

\section{Site specific disturbance of tooth formation and eruption}

The present study attempted a longitudinal observation of the developmental processes of molars and periodontal tissues in $c$-src deficient mice and has clearly demonstrated that the failure of eruption of molar teeth in $c$-src deficient mice is not a universal phenomenon common to all types of molars but rather site-specific and/or tooth type-specific in these animals. It has become apparent that the characteristic constriction of the crown of the upper 1st molar is due to a localized mechanical blockade of expansion of the tooth germ by bone spicules at the early stage of development. The partial destruction of the upper 1st molars restricted exclusively to the proximal portion of the crown of these teeth indicates a strict site-specificity of the disturbance of tooth development even within a single tooth in $c$-src deficient mice.

The Severe disturbance of root formation in the upper 1 st molar of these mice also appears to be a consequence of disturbed eruptive movement since there was no structural abnormality in the Hertwig's epithelial root sheath at early stages of root formation in our observation (data not shown).

\section{Osteoclasts in the eruption pathway}

It is well documented that the osteoclasts in $c$-src deficient mice lack a ruffled border and hence are hypofunctional (Soriano et al., 1991; Boyce et al., 1992). In the electron microscopic observations (Fig. 6e), however, the "hypofunctional osteoclasts" in the eruption pathway of the molars of $c-s r c$ deficient mice appeared to retain some bone resorbing activities, thus suggesting their contribution to excavation of the eruption pathway for the molar teeth. In fact, the tooth crown of at least one half of the 2nd molars examined in this study fully or partially moved through a wide opening of the eruption pathway in $c$-src deficient animals (Fig. 3, Table 1) despite extremely narrow apical openings of the alveolar sockets at day 6 of postnatal development (Fig. 6a-d).

\section{Spatial relation of developing molar tooth germs with surrounding bones}

Although quantitative data is lacking in this study, it does not seem likely that the bone resorbing activity of osteoclasts associated with the alveolar sockets of the individual molar tooth germs in $c$-src deficient mice differs among the tooth types since the abnormality of osteoclasts is autonomous (Lowe et al., 1993), and hence the structure and function of the individual osteoclasts 
are expected to be equally affected by $c-s r c$ deficiency. Accordingly, the characteristic spatial relation of the individual molar tooth germs with the surrounding bones (alveolar wall) appears to be a key to explain the differential effects of $c$-src deficiency on molar tooth development. In this regard, it is of particular interest that, even in WT animals, the alveolar wall of the upper 1st molar is extremely closely apposed to the enamel organ and, in some cases, could cause deformation of the enamel organ. It is also noteworthy that, in WT animals, the bone spicules seemingly indenting the enamel organ in the upper 1st molar are associated with a certain number of active osteoclasts, suggesting the ongoing resorption of the respective bone spicules (Fig. 5e). It is thus indicated that, in WT animals, resorption of the inner aspect of the alveolar socket of the upper 1st molar is barely managed by the osteoclasts, and minimal space is provided to accommodate the rapidly growing tooth germ even under physiological conditions. Such a close spatial relation between the growing tooth and the surrounding bone is exclusive to the upper 1st molar and not seen in all other types of molars.

Considering these facts together, the differential effect of $c$-src deficiency on the development and eruption of the individual types of molar teeth in homozygous mice is thought to be attributable to the given spatial relation of the growing tooth germs with surrounding bones in the presence of hypofunctional osteoclasts, rather than a putative differential population and/or bone resorbing activity of the osteoclasts associated with the respective molars.

\section{c-src deficiency and osteoblast function}

It has been reported that $c-s r c$ deletion upregulates alkaline phosphatase, the Osf $2 / \mathrm{Cbfa} 1$ transcription factor, parathyroid hormone/parathyroid hormone-related protein (PTH/PTHrP) receptors, osteocalcin, and proalpha 2(I) in $c$-src deficient osteoblasts, all indicating an enhancement of the differentiation and bone forming function of these cells in vitro (Marzia et al., 2000). On the other hand, in vivo data only indicate an increase in bone volume but no such changes in the bone forming rate in $c$-src deficient mice (Amling et al., 2000). Moreover, in the jaw bones of $c$-src deficient mice, the osteoblasts in the vicinity of the tooth (germs) tend to be flattened and, in the aging process, disappear from the bone surface, leaving it open to the tissue fluid (Baba et al., 2006). Taking these and current observations together, it is suggested that the defective growth and failure of eruption of the upper 1st molars is attributable primarily to the impaired bone resorbing function of osteoclasts rather than any upregulated function of the osteoblasts associated with the alveolar bone.

It is well known that, in normal animals, the enamel organ of the growing tooth germs, particularly the stellate reticulum, expresses distinct mRNA signals for PTHrP and that the dental follicle cells and bone cells, most likely osteoblasts in the alveolar bone, express PTH/ PTHrP receptors (Philbrick et al., 1998). Throughout the pre-eruptive and eruptive processes of tooth development, PTHrP derived from the growing tooth germs are thought to stimulate the nearby osteoblasts and, indirectly enhance osteoclastic bone resorption via RANK/RANKL interactions in the alveolar bone (Nakchbandi et al., 2000). In fact, PHTrP deficient mice lack both incisors and molars because of the severe destruction of tooth germs due to a massive invasion of bone spicules in early development (Liu et al., 1998; Philbrick et al., 1998; Liu et al., 2000; Kitahara et al., 2002).

As previously mentioned, $c$-src deficiency upregulates $\mathrm{PTH} / \mathrm{PTHrP}$ receptors in osteoblasts in vitro (Marzia et al., 2000). One may speculate that the mild disturbance of molar tooth development and its eruption in $c$-src deficient mice relative to the far severer disturbances seen in PTHrP deficient mice is attributable at least in part to the upregulation of $\mathrm{PTH} / \mathrm{PTHrP}$ receptors in the follicle cells and osteoblasts in $c$-src deficient mice, which might facilitate osteoclastic resorption of the alveolar bone although the osteoclasts are devoid of a ruffled border. In fact, Boyce et al. (1992) injected PTH and PTHrP into calvarial subcutaneous tissue of $c$-src deficient mice and found that both bone resorption stimulators induced 7 to 8 times larger numbers of osteoclasts in the calvarial bone relative to those in $c$-src deficient control animals in vivo.

\section{Lack of occlusal stimuli and conformation of periodontal ligament}

Among the osteopetrotic murine models, full or partial eruption of molar teeth is a characteristic feature of $c$ src deficiency. In $c$-src deficient mice, however, no direct occlusal contact can be expected between the upper and lower molars since the "erupted" teeth are mostly covered by a thick fold of buccal oral mucosa (Fig. 3). Accordingly, only limited mechanical stimuli, if any, should be applied to the molars via a mucosal tissue.

It is well known that the mechanical stimuli of functional occlusion is essential for the development and maintenance of the periodontal ligament (Tanaka $e t$ al., 1998; Muramoto et al., 2000). Differential staining intensity of the periodontal ligament with a periostin antibody among the different types of molars of $c$ src deficient mice as shown in Figure 3 may therefore 
represent the differential mechanical stimuli, if any, applied to the individual teeth via a thick oral mucosa rather than intrinsic differences in the levels of periostin expression among the teeth. Periostin is an extracellular matrix protein reportedly required for the eruption of incisors in mice (Kii et al., 2006). Interestingly, however, molar tooth eruption is not significantly affected in $c$ src deficient mice, and all upper and lower molars are shown to be fully erupted (Rios et al., 2005). Therefore, we assume that the poor development of the periodontal ligament in $c$-src deficient mice is not a factor in the defective eruption of molars but rather a consequence of a lack of appropriate mechanical stimuli, due to defective eruption.

\section{Possible direct effect of c-src deficiency on growing molar tooth germs}

Predentin is a non-mineralized matrix layer located along the innermost portion of the circumpulpal dentin formed by the odontoblasts. The thickness of the predentin layer depends on the balance between the speeds of matrix deposition and its mineralization along the mineralization front where the predentin matrix turns into dentin. A thick predentin layer may represent either upregulation of the dentin matrix formation or a delayed mineralization or mild hypomineralization of predentin matrix. The globular mineralization of dentin in which mineralized spherules of dentin are interposed by non-mineralized or poorly mineralized dentin matrix (interglobular dentin) (Mjor, 1972) is also a feature either of rapidly forming dentin or hypomineralized dentin. It is important to note that, at certain regions of the teeth, the sum of the thickness of dentin and underlying predentin is not much different between the molars of WT and homozygous animals, implicating an identical rate of dentin matrix formation regardless of the presence or absence of $c$ $s r c$. Therefore, thick predentin in the 1st molars of $c-s r c$ deficient mice in early postnatal development and distinct globular mineralization in the following developmental period together appear to represent hypomineralization rather than accelerated matrix formation of dentin in these teeth. Though indistinct, such mild and transient hypomineralization of dentin matrix in early stage dentinogenesis is a universal phenomenon common to all types of molars in $c$-src deficient animals, and hence can be the direct effect of $c$-src deficiency so far identified other than that on the osteoclasts. Hindered root formation in the upper 1st molar is thought to be a secondary phenomenon related to the early immobilization of the tooth germs by the insertion of bones spicules and resultant shortage of the space for root elongation within the bottom of the alveolar socket.

\section{References}

Amling M, Neff L, Priemel M, Schilling AF, Rueger JM, Baron R: Progressive increase in bone mass and development of odontomas in aging osteopetrotic c-srcdeficient mice. Bone 27: 603-610 (2000).

Baba O, Miyata A, Abe T, Shibata S, Nakano Y, Terashima T, Oda T, Kudo A, Takano Y: Formation of acellular cementum-like layers, with and without extrinsic fiber insertion, along inert bone surfaces of aging c-Src gene knockout mice. Eur J Oral Sci 114: 524-534 (2006).

Boyce BF, Chen H, Soriano P, Mundy GR: Histomorphometric and immunocytochemical studies of srcrelated osteopetrosis. Bone 14: 335-340 (1993).

Boyce BF, Yoneda T, Lowe C, Soriano P, Mundy GR: Requirement of pp60c-src expression for osteoclasts to form ruffled borders and resorb bone in mice. $J$ Clin Invest 90: 1622-1627 (1992).

Burstone MS: Histochemical demonstration of phosphatases in frozen sections with naphthol ASphosphates. J Histochem Cytochem 9: 146-153 (1961).

Cantley LC, Auger KR, Carpenter C, Duckworth B, Graziani A, Kapeller R, Soltoff S: Oncogenes and signal transduction. Cell 64: 281-302 (1991).

Eiseman E, Bolen JB: src-related tyrosine protein kinases as signaling components in hematopoietic cells. Cancer Cells 2: 303-310 (1990).

Helfrich MH: Osteoclast diseases and dental abnormalities. Arch Oral Biol 50: 115-122 (2005).

Horiuchi K, Amizuka N, Takeshita S, Takamatsu H, Katsuura M, Ozawa H, Toyama Y, Bonewald LF, Kudo A: Identification and characterization of a novel protein, periostin, with restricted expression to periosteum and periodontal ligament and increased expression by transforming growth factor beta. $J$ Bone Miner Res 14: 1239-1249 (1999).

Jung H S, Hitoshi Y, Kim HJ: Study on tooth development, past, present, and future. Microsc Res Tech 60: 480-482 (2003).

Kii I, Amizuka N, Minqi L, Kitajima S, Saga Y, Kudo A: Periostin is an extracellular matrix protein required for eruption of incisors in mice. Biochem Biophys Res Commun 342: 766-772 (2006).

Kitahara Y, Suda N, Kuroda T, Beck F, Hammond VE, Takano $\mathrm{Y}$ : Disturbed tooth development in parathyroid hormone-related protein (PTHrP)-gene knockout mice. Bone 30: 48-56 (2002). 
Liu J G, Tabata M J, Fujii T, Ohmori T, Abe M, Ohsaki Y, Kato J, Wakisaka S, Iwamoto M, Kurisu K: Parathyroid hormone-related peptide is involved in protection against invasion of tooth germs by bone via promoting the differentiation of osteoclasts during tooth development. Mech Dev 95: 189-200 (2000).

Liu JG, Tabata MJ, Yamashita K, Matsumura T, Iwamoto M, Kurisu K: Developmental role of PTHrP in murine molars. Eur J Oral Sci 106 Suppl 1: 143-146 (1998).

Lowe C, Yoneda T, Boyce BF, Chen H, Mundy GR, Soriano P: Osteopetrosis in Src-deficient mice is due to an autonomous defect of osteoclasts. Proc Natl Acad Sci USA 90: 4485-4489 (1993).

Marks S C, Jr.: The basic and applied biology of tooth eruption. Connect Tissue Res 32: 149-157 (1995).

Marks SC Jr, Cahill DR, Wise GE: The cytology of the dental follicle and adjacent alveolar bone during tooth eruption in the dog. Am J Anat 168: 277-289 (1983).

Marks SC Jr, Schroeder H E: Tooth eruption: theories and facts. Anat Rec 245: 374-393 (1996).

Marzia M, Sims NA, Voit S, Migliaccio S, Taranta A, Bernardini S, Faraggiana T, Yoneda T, Mundy GR, Boyce BF, Baron R, Teti A: Decreased c-Src expression enhances osteoblast differentiation and bone formation. $J$ Cell Biol 151: 311-320 (2000).

Mjor IA: Human coronal dentine: structure and reactions. Oral Surg Oral Med Oral Pathol 33: 810-823 (1972).

Muramoto T, Takano Y, Soma K: Time-related changes in periodontal mechanoreceptors in rat molars after the loss of occlusal stimuli. Arch Histol Cytol 63: 369-380 (2000).

Nakchbandi IA, Weir EE, Insogna KL, Philbrick WM, Broadus AE: Parathyroid hormone-related protein induces spontaneous osteoclast formation via a paracrine cascade. Proc Natl Acad Sci USA 97: 72967300 (2000).

Philbrick WM, Dreyer BE, Nakchbandi IA, Karaplis AC: Parathyroid hormone-related protein is required for tooth eruption. Proc Natl Acad Sci USA 95: 1184611851 (1998).
Rios H, Koushik SV, Wang H, Wang J, Zhou HM, Lindsley A, Rogers R, Chen Z, Maeda M, KruzynskaFrejtag A, Feng JQ, Conway SJ: Periostin null mice exhibit dwarfism, incisor enamel defects, and an earlyonset periodontal disease-like phenotype. Mol Cell Biol 25: 11131-11144 (2005).

Soriano P, Montgomery C, Geske R, Bradley A: Targeted disruption of the c-src proto-oncogene leads to osteopetrosis in mice. Cell 64: 693-702 (1991).

Stehelin D, Varmus HE, Bishop JM, Vogt PK: DNA related to the transforming gene(s) of avian sarcoma viruses is present in normal avian DNA. Nature 260: 170-173 (1976).

Tanaka K, Iida J, Soma K: Effect of hypofunction on the microvasculature in the periodontal ligament of the rat molar. J Jap Orthod Soc 57: 180-188 (1998).

Tanaka S, Takahashi N, Udagawa N, Sasaki T, Fukui Y, Kurokawa T, Suda T: Osteoclasts express high levels of p60c-src, preferentially on ruffled border membranes. FEBS Lett 313: 85-89 (1992).

TenCate A: Oral histology: Development, structure and function. 5th ed, Mosby-Year Book, 1998.

Tiffee JC, Xing L, Nilsson S, Boyce BF: Dental abnormalities associated with failure of tooth eruption in src knockout and op/op mice. Calcif Tissue Int 65: 53-58 (1999).

Wise GE, Frazier-Bowers S, D'Souza RN: Cellular, molecular, and genetic determinants of tooth eruption. Crit Rev Oral Biol Med 13: 323-334 (2002).

Yoda S, Suda N, Kitahara Y, Komori T, Ohyama K: Delayed tooth eruption and suppressed osteoclast number in the eruption pathway of heterozygous Runx2/Cbfa1 knockout mice. Arch Oral Biol 49: 435442 (2004).

Yoshida H, Hayashi S, Kunisada T, Ogawa M, Nishikawa S, Okamura H, Sudo T, Shultz LD: The murine mutation osteopetrosis is in the coding region of the macrophage colony stimulating factor gene. Nature 345: 442-444 (1990). 